\title{
Caracterização ambiental por meio do mapeamento temático utilizando Sistemas de Informação Geográfica no Alto Camaquã - RS
}

\author{
Environmental characterization through the thematic mapping using geographic \\ information systems in the Alto Camaquã - RS
}

\author{
Roberta Aparecida Fantine ${ }^{1}$, Ewerthon Cezar Schiavo Bernardi², Varlen dos Santos \\ Nassinhack $^{3}$, Ana Caroline Paim Benedetti ${ }^{4}$
}

${ }^{1}$ Engenheira Florestal, Universidade Federal do Pampa, São Gabriel, RS Brasil roberta.fantinel@bol.com.br

${ }^{2}$ Mestrando em Engenharia Ambiental, Universidade Federal de Santa Maria, RS Brasil bernardi.ecs@hotmail.com

${ }^{3}$ Acadêmico do Curso de Gestão Ambiental, Universidade Federal do Pampa, São Gabriel, RS Brasil varlennassinhack@hotmail.com

${ }^{4}$ Engenheira Florestal, Professora Dra, Universidade Federal de Santa Maria, Colégio Politécnico da UFSM, RS , Santa Maria anacaroline@politecnico.ufsm.br

\section{Resumo}

O estudo objetivou caracterizar o território do Alto Camaquã, a partir do mapeamento temático utilizando Sistemas de Informação Geográfica. A metodologia consistiu na importação e processamento de imagens SRTM e imagens do satélite Landsat 8, no aplicativo SPRING 5.1.8. Os resultados permitiram evidenciar que a classe temática "floresta" é a mais significativa da área de estudo com 8.491,43 $\mathrm{km}^{2}$, sendo explicada pelo aumento de empresas de silvicultura, a classe "campo" possui a segunda maior área com 8.259,02 km², seguido do "solo exposto" (5.586,05 km²), "água" $\left(609,70 \mathrm{~km}^{2}\right)$ e área urbana com $\left(31,25 \mathrm{~km}^{2}\right)$. As áreas de altitudes ficaram entre $(100-150 \mathrm{~m}),(150-200 \mathrm{~m}),(200-250 \mathrm{~m}),(250-300 \mathrm{~m})$ e a altitude $(300-350 \mathrm{~m})$ ocupam a maior parte da extensão territorial (86,30\%) caracterizado por campo e solo exposto. As menores altitudes $(0-50 \mathrm{~m}),(50-100 \mathrm{~m})$, $(350-400 m),(400-450 m)$ e $(450-500 m)$ com 13,70\% formadas por florestas. Quanto à declividade o predomínio foi dos relevos do tipo plano ( $0 \%$ a 5\%), e suave ondulado (5\% a 12\%) totalizando $84,40 \%$ da área. As demais classes de declividade (12\% a 20\%) apresentam relevo moderado e a declividade com (20\% a 30\%) relevo ondulado totalizando 14,83\% da área. Acima de 30\% corresponde ao relevo fortemente ondulado, totalizando 0,77\%. Através do mapeamento do uso e cobertura da terra, da altimetria e da declividade foi possível fornecer bases para avaliar os diferentes usos, compreender a dinâmica e promover o melhor aproveitamento dessas áreas, possibilitando assim, uma utilização racional da área do estudo.

Palavras-chave: Clinografia; Hipsometria; Sensoriamento Remoto; Uso e Cobertura da Terra.

\begin{abstract}
The study aimed to characterize the territory of the High Camaqua from the thematic mapping using Geographic Information Systems. The methodology consisted in importing and processing SRTM images and pictures Landsat 8, SPRING 5.1.8 application. The results have highlighted that the thematic class "forest" is the most significant of the study area with 8491,43 $\mathrm{km}^{2}$ and is explained by the increase of forestry companies, the "field" class has the second largest area of 8259,02 $\mathrm{km}^{2}$, followed by the "bare soil" $\left(5586,05 \mathrm{~km}^{2}\right)$, "water" $\left(609,70 \mathrm{~km}^{2}\right)$ and urban area with $\left(31,25 \mathrm{~km}^{2}\right)$. The elevation higher were between $(100-150 m),(150-200 m),(200-250 m),(250-300 m)$ and altitude $(300-350 m)$ occupy most of the land area $(86,30 \%)$ characterized by field and exposed soil. The elevation lower $(0-50 \mathrm{~m}),(50-100 \mathrm{~m}),(350-400 \mathrm{~m}),(400-450 \mathrm{~m})$ and $(450$ $500 \mathrm{~m})$ with $13,70 \%$ formed by forests. How much the declivity was the predominance of type relief $(0 \%$ to $5 \%$ ), and soft wavy ( $5 \%$ to $12 \%$ ) totaling $84,40 \%$ of the area. The other classes declivity ( $12 \%$ to $20 \%$ ) of relief moderate, with the declivity $(20 \%$ to $30 \%$ ) totaling of area relief wavy $14,83 \%$. Over $30 \%$ corresponds to strongly wavy relief, totaling $0,77 \%$. By mapping the use and land cover, the altitude and slope it was possible to provide a basis for evaluating the different uses, understand the dynamics and promote the best use of these areas, thus enabling rational use of the study area.
\end{abstract}

Keywords: Clinografia; Hipsometria; Remote Sensing; Use and Land Cover. Recebido: 02/04/2016 Aceito: 02/05/2016 


\section{Introdução}

A classificação do uso da terra de uma determinada região ou município é importante para a compreensão dos padrões de organização do espaço e suas transformações.

O conhecimento sobre o uso da terra para Santos (2004) caracteriza-se por diferentes classes temáticas que compõe a área em estudo, além disso, o mapeamento é importante para solucionar os problemas decorrentes da degradação dos solos, das terras agricultáveis, da perda do habitat da fauna entre outras aplicações.

A utilização de dados atualizados do uso e cobertura da terra para Rosa (2003) é ampla, pois identifica áreas com processos erosivos avançados, avaliam os impactos ambientais, pode ser realizado o inventário de recursos hídricos, o controle de inundações, identificação e a formulação de políticas econômicas.

De acordo com Pereira (1994) o levantamento de dados de uma determinada região específica ou em nível de município é importante para mostrar a distribuição espacial das atividades de exploração e conservação.

Conforme Pacheco (1998) o conhecimento atualizado das informações sobre as mudanças e as áreas ocupadas pelos recursos naturais, urbanização e edificações se tornam cada vez mais necessárias aos legisladores e planejadores. Outra característica importante para o planejamento ordenado de um território é o conhecimento sobre a clinografia do terreno.

O mapeamento da declividade segundo Vieira et al. (2009), é uma das formas de obter dados do meio físico, constituindo elemento importante no que diz respeito à potencialidade de ocupação; a influência sobre a aptidão agrícola de uma determinada área, influência no escoamento superficial, facilitando ou dificultando a erosão dos solos.O mapa de declividade conforme Cassol (1996) quando analisado de forma independente apresenta resultados aceitáveis, pois existe uma legislação relativa ás áreas urbanas e rurais, onde os intervalos de classes de declividade foram testados nos distintos campos do saber.

O mapeamento hipsométrico para Loch (2006) associa as formas naturais da paisagem com a distinção de diferenças na altitude, elaborando assim, uma melhor identificação das maiores e menores altitudes de uma determinada região.

Desta forma, produtos do Sensoriamento Remoto obtidas por plataformas orbitais e por Sistemas de Informação Geográfica (SIG) tornaram-se fundamentais para realizar o monitoramento do uso e cobertura da terra e obter informações para avaliar a dinâmica da paisagem (NOVO 2008).

O Sensoriamento Remoto fez com que o homem pudesse obter informações sobre os recursos naturais e o meio ambiente, sendo uma ferramenta complementar auxiliando em trabalhos temáticos e de levantamentos (CURRAN, 1985).

Para Valerio Filho (1995) as técnicas do Sensoriamento
Remoto auxiliam na deteç̧ão automática da dinâmica da cobertura da terra, sendo essencial para a utilização de sistemas de alta capacidade para o tratamento e análise de informações multitemáticas.

Segundo Fabris (1995) e Asrar (1989) a importância e as vantagens do Sensoriamento Remoto consiste no mapeamento, monitoramento de recursos naturais, a proteção de ambientes decorrentes da exploração degradante, proporcionando o aproveitamento do uso da terra e a elaboração e atualização de mapas, em relação as suas particularidades geoeconômicas e recursos financeiros.

Neste contexto, o objetivo do trabalho foi caracterizar o território do Alto Camaquã, localizado no Estado do Rio Grande do Sul, através mapeamento temático utilizando Sistemas de Informação Geográfica, tendo como finalidade fornecer bases para analisar e avaliar as diferentes formas de uso e cobertura, promovendo e compreendendo melhor a dinâmica do uso e cobertura da terra.

\section{Materiais e métodos}

\section{Caracterização da área de estudo}

A área do presente trabalho corresponde aos municípios que fazem parte do território do Alto Camaquã (Bagé, Caçapava do Sul, Dom Pedrito, Hulha Negra, Lavras do Sul, Pinheiro Machado, Piratini e Santana da Boa Vista) localizada no Estado do Rio Grande do Sul. O território do Alto Camaquã situa-se entre as coordenadas $30^{\circ} 08^{\prime}$ e $31^{\circ} 53^{\prime}$ de latitude Sul e $52^{\circ} 51^{\prime}$ e $55^{\circ} 09^{\prime}$ de longitude Oeste (Figura 1)

A vegetação predominante é caracterizada por campo e floresta, sendo as florestas mais desenvolvidas junto às faixas ciliares de rios e arroios, enquanto os campos predominam os campos limpos sem componentes lenhosos e os campos sujos com arbustos e subarbustos (OVERBECK et al., 2009).

Os campos do Alto Camaquã variam desde formações de gramíneas, espécies herbáceas, arbustos e subarbustos, vegetação essa que é caraterizada na região por algumas espécies do gênero Baccharis e pela espécie Dodonaea viscosa (BOLDRINI e EGGERS, 1997; RAMBO, 1956).

Os solos predominantes na área do estudo são classificados como argissolos e neossolos (STRECK et al., 2008). O argissolo caracteriza-se por ser um solo profundo e bem drenado, além disso, ocorre em relevos suaves ondulados e ondulados e podem ser usados com culturas anuais e campo nativo, preferencialmente com plantio direto e em rotação de culturas com plantas protetoras e recuperadoras do solo durante o inverno (STRECK et al., 2002).

De maneira geral, os neossolos apresentam profundidade variada, são formações muito recentes, possui grandes restrições ao uso agrícola, alta suscetibilidade à erosão hídrica, baixa capacidade de infiltração e ar- 


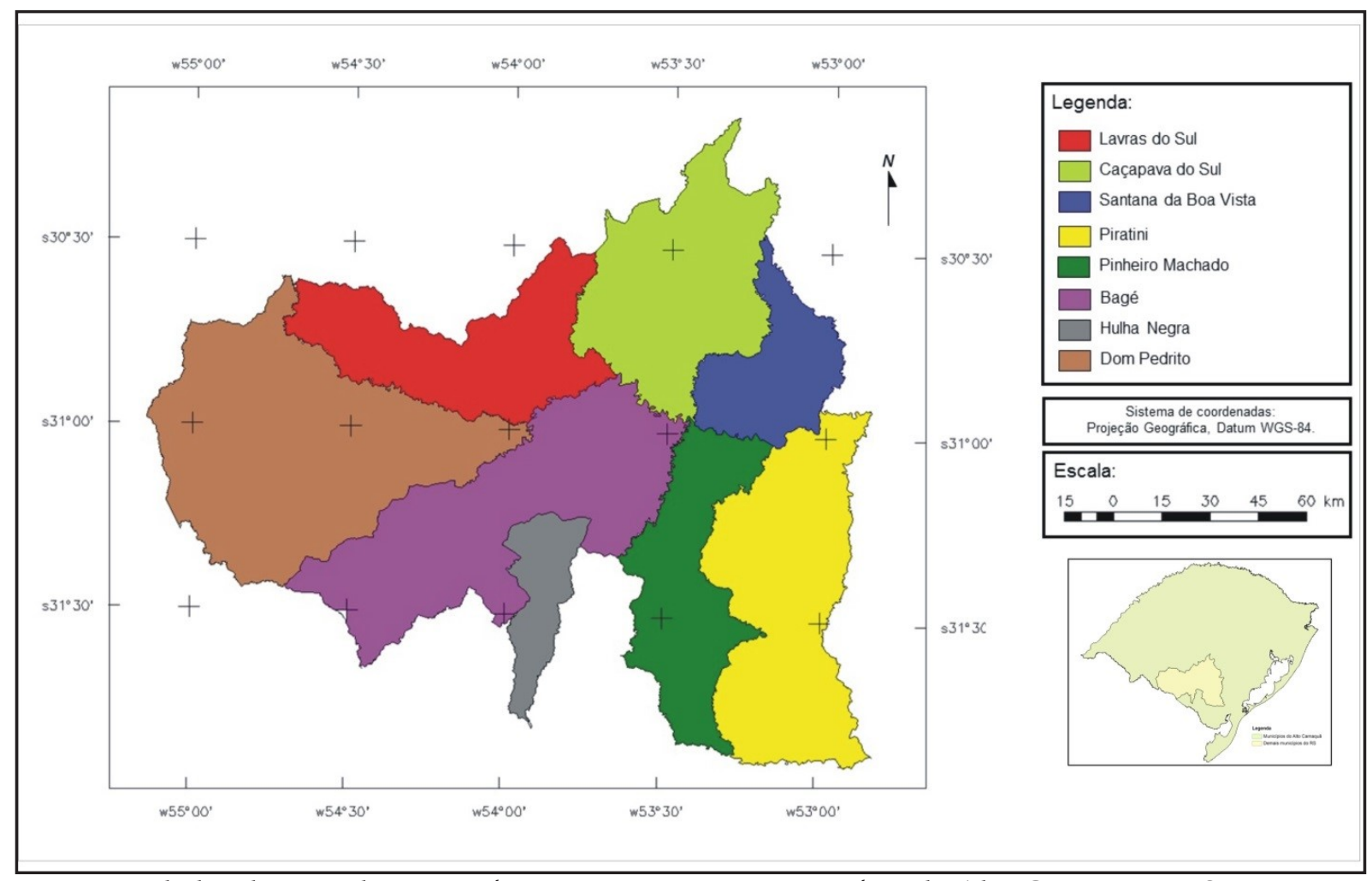

Figura 1 - Mapa da localização dos municípios que compõem o território do Alto Camaquã - RS

mazenamento de água no solo (STRECK et al., 2008).

Os solos predominantes segundo Neske (2009) são rasos e pedregosos, apresentam afloramentos de rochas em áreas de relevo ondulado, sendo vulneráveis à erosão e restrições ao uso agrícola. Ainda de acordo com Figueiró et al. (2011) o Alto Camaquã possui uma combinação de elementos abióticos, como afloramentos rochosos, diversidade biológica de fauna e flora e características culturais e socioeconômicas únicas.

\section{Elaboração do mapa de uso e cobertura da terra}

O estudo iniciou-se através da elaboração do mapa de uso e cobertura da terra dos municípios que compõem o território do Alto Camaquã. Dessa forma, foram estabelecidas cinco classes temáticas, de acordo com a análise visual das imagens, descritas a seguir:

Floresta: foram consideradas as formações vegetais arbóreas primárias e secundárias (vegetação de médio e de grande porte). Nesta classe englobam as capoeiras, matas de galeria, matas ciliares e as florestas nativas e plantadas (MOREIRA, 2003). Campo: compreende as áreas de vegetação rasteira, pequenas áreas de pastagens cultivadas e campo. Solo exposto: inclui áreas de agricultura em pousio ou preparo de solo e as áreas sem vegetação. Segundo Anderson et al. (1979), essa categoria apresenta alta refletância, suas formas geométricas são bem definidas e a tonalidade varia de acordo com a ocupação. Água: considera-se os rios, as barragens, os açudes, banhados dentre outros corpos d'água. Mancha urbana: compreende as zonas urbanas dos municípios do território do Alto Camaquã.

A classificação de uma imagem para Fitz (2008) é a identificação de determinados elementos nela presente pela associação de cada um de seus pixels a uma determinada classe já pré-estabelecida.

Foram necessárias quatros imagens do sensor do satélite Landsat 8, sensor OLI (Operational Land Imager) como mostra a Tabela 1, obtidas por meio da página eletrônica da USGS (United States Geological Survey) para a confecção do mapa temático do uso e cobertura da terra.

Tabela 1 - Órbita/ponto e mês/ano da passagem das imagens Landsat 8

\begin{tabular}{|c|c|}
\hline \hline Órbita/Ponto & Mês/Ano da Passagem \\
\hline $222 / 081$ & Novembro de 2013 \\
\hline $222 / 082$ & Novembro de 2013 \\
\hline $223 / 081$ & Novembro de 2013 \\
\hline $223 / 082$ & Novembro de 2013 \\
\hline
\end{tabular}


O processamento dos dados sucedeu-se com a importação preliminar no software SPRING (Sistema de Processamento de Informações Georreferenciadas) versão 5.1.8, das bandas 4, 5 e 6 das cenas Landsat 8 .

Posteriormente, foi gerado um mosaico de cada banda e atribuído um canal de cor para cada plano de informação, resultando na composição da banda 4 (azul), 5 (verde) e 6 (vermelho). A próxima etapa consistiu na classificação da imagem com base no método de classificação supervisionada por pixels, empregando o classificador de Máxima Verossimilhança (MaxVer). Esse classificador conforme Meneses e Sano (2012) consideram a ponderação das distâncias entre as médias dos valores dos pixels das classes, utilizando parâmetros estatísticos.

Em seguida o plano de informação contendo a imagem classificada passou por uma edição matricial, que tem por finalidade corrigir certas incertezas entre as classes que possam ter ocorrido no momento da classificação.

\section{Aquisição das cartas SRTM (Shuttle Radar Topography Misson)}

Para abranger a área de estudo foram importadas quatro imagens de radar SRTM (Shuttle Radar Topography Misson), correspondente às cartas topográficas SH-22-Y-A, SH-21-Z-B, SH-22-Y-C e SH-21-Z-D, em escala 1:250.000, correspondentes aos municípios de Bagé, Caçapava do Sul, Dom Pedrito, Hulha Negra, Lavras do Sul, Pinheiro Machado, Piratini e Santana da Boa Vista. Estas imagens foram adquiridas gratuitamente, através do download no site da Embrapa - Brasil em Relevo.

\section{Processamento dos mapas hipsométrico e cli- nográfico}

O desenvolvimento do banco de dados, a importação e o processamento das imagens do modelo digital de elevação foram executados no software SPRING versão 5.1.8. Após a importação dos dados SRTM foi gerado um mosaico utilizando o interpolador "vizinho mais próximo". Em seguida este mosaico foi reamostrado, de 90 para 30 metros utilizando o interpolador bicúbico, para que houvesse uma melhor resolução espacial nos mapas finais.

A partir do mosaico SRTM foram gerados planos de informações contendo declividade e hipsometria dos municípios que compõem o território do Alto Camaquã.

Para o desenvolvimento do mapa de declividade, primeiramente foi gerada uma categoria temática para a qual se atribuíram as seguintes classes: 0 a $5 \% ; 5$ a $12 \% ; 12$ a 20\%; 20 a 30\%; e >30\% estabelecidas por De Biasi (1992). Posteriormente foi gerada uma grade de declividade com os valores em porcentagens e resolução espacial de trinta metros a partir da função "Declividade" disponível no módulo Modelo Numérico do Terreno do SPRING.

A grade foi fatiada adotando-se como fatias as classes criadas na categoria, a partir da função "Fatiamento" desse mesmo módulo. Para o plano hipsométrico, foi criada uma nova categoria temática dividindo o intervalo de 0 a 500 metros em diferentes classes, com passo de 50 metros cada e em seguida, o modelo digital de elevação foi fatiado conforme as classes elaboradas.

O mapa hipsométrico foi elaborado de acordo com um sistema de graduação de cores, onde as cores frias como, por exemplo, a tonalidade de verde representa uma cota de baixa altitude, enquanto que as cores quentes como o marrom representam altitudes elevadas.

\section{Resultados e discussão}

\section{Mapeamento do uso e cobertura da terra}

Para a análise do uso e cobertura da terra e a realização da classificação digital (Figura 2) foram utilizadas imagens do Landsat 8 sensor OLI do mês de novembro de 2013, analisado e quantificado as classes temáticas, conforme a Tabela 2.

A classe temática "floresta" predominante no território do Alto Camaquã totalizou $8.491,43 \mathrm{~km}^{2}$, esse predomínio pode ser explicado principalmente pelo aumento de empresas do ramo da silvicultura de povoamentos de Pinus sp. e Eucalyptus sp., que vem transformando a paisagem do Alto Camaquã.

Os cultivos em áreas inadequadas das espécies florestais Eucalyptus sp. e Pinus sp. segundo Chomenko (2007, p. 6) "poderão conduzir a graves conflitos, seja pelo uso de recursos escassos, pela posse da terra ou ainda pela própria perda da identidade cultural regional". Esta classe também é representada pela vegetação arbórea, que se encontra ao longo dos cursos d'água e florestas esparsas.

A classe "campo" possui a segunda maior ocupação com $8.259,02 \mathrm{~km}^{2}$, nesta área ocorre à prática da pecuária extensiva caracterizada pela presença de rebanhos de bovinos e ovinos. De acordo com Degrandi (2011) os campos com predomínio de espécies gramíneas de raízes rasas podem sofrer com a alteração de sua cobertura vegetal devido às atividades da silvicultura, já que, os monocultivos florestais possuem raízes mais profundas que atingem o lençol freático com maior facilidade.

Segundo Gassmann (2009) os campos do Bioma Pampa onde está inserido o território do Alto Camaquã possui uma vasta riqueza de espécies, no qual é atribuído a sua localização de transição entre o clima tropical e temperado, bem como à sua variação de substrato geológico e de altitude (OVERBECK, 2009).

Quanto a classe "solo exposto" a área totalizou 5.586,05 $\mathrm{km}^{2}$, correspondendo a solos em pousio, áreas abandonadas, áreas preparadas para plantio e voçorocas. Essa classe vem sofrendo constantes modificações com a ação antrópica através da silvicultura de povoamentos florestais, outro fator são os terrenos que são deixados descobertos durante uma boa parte do ano ou em áreas 


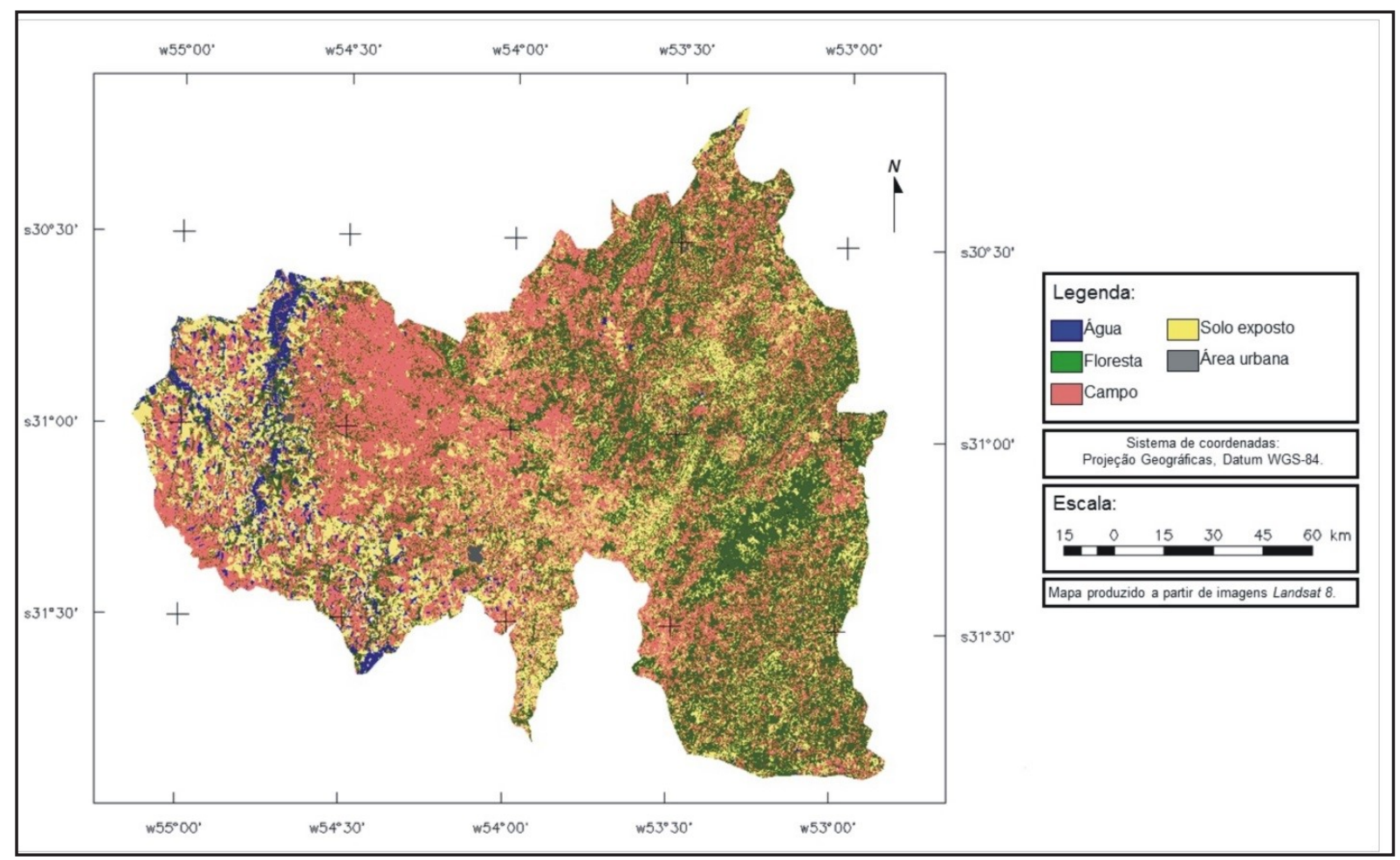

Figura 2 - Mapa do uso e cobertura da terra dos municípios localizados no território do Alto Camaquã - RS

Tabela 2 - Quantificação do uso e cobertura da terra

\begin{tabular}{|c|c|c|}
\hline \hline Classes Temáticas & Área Total $\left.\mathbf{( k m}^{\mathbf{2}}\right)$ & $\mathbf{( \% )}$ \\
\hline Água & 609,70 & $2,65 \%$ \\
\hline Floresta & $8.491,43$ & $36,96 \%$ \\
\hline Campo & $8.259,02$ & $35,94 \%$ \\
\hline Área urbana & 31,25 & $0,14 \%$ \\
\hline Solo exposto & $5.586,05$ & $24,31 \%$ \\
\hline Total & $\mathbf{2 2 . 9 7 7 , 4 5}$ & $\mathbf{1 0 0}$ \\
\hline \hline
\end{tabular}

onde ocorre o superpastoreio, aumentando a densidade do solo, com excessivo pisoteio do gado (GUERRA e MENDONÇA, 2004).

Ainda de acordo com Chomenko (2007) os solos podem apresentar maior acidez e redução na sua fertilidade, incremento de erosão, em função da alteração da estrutura do solo e redução de permeabilidade da água.

O Alto Camaquã é uma região que, de acordo com os mapas elaborados pela FEPAM (2007) para o Zoneamento Ambiental do Rio Grande do Sul, apresenta restrição para as atividades silvícola, por possuir solos rasos na sua maior extensão, além disso, possui alta deficiência hídrica no solo nos meses de verão e menor disponibilidade hídrica superficial.

Quanto à classe "água" apresenta uma área menor de ocupação no território do Alto Camaquã com 609,70 km². Conforme Lucas (2013) a ausência de um sistema público de distribuição de água e a cultura local da população do Alto Camaquã, ao longo dos anos vem utilizando as nascentes como fonte de água para abastecimento humano e para a pecuária familiar, além disso, a população utiliza o conhecimento empírico para a construção de reservatórios, popularmente conhecido na região por "cacimbas" para distribuição de água.

A classe "área urbana" corresponde às zonas urbanas dos 11 municípios que fazem parte do território do Alto Camaquã representando uma área total de 31,25 km².

\subsection{Mapeamento hipsométrico e clinográfico}

O mapa hipsométrico (Figura 3) representa a altimetria da área de estudo e foi elaborado a partir dos dados SRTM. Foram geradas curvas de nível equidistantes 50 metros, totalizando 10 classes altimétricas. O território do Alto Camaquã apresentou cotas baixa de 50 metros e como cota mais alta 500 metros.

As altitudes entre (100 - 150 metros), (150 - 200 metros), (200 - 250 metros), (250 - 300 metros $)$ e a 


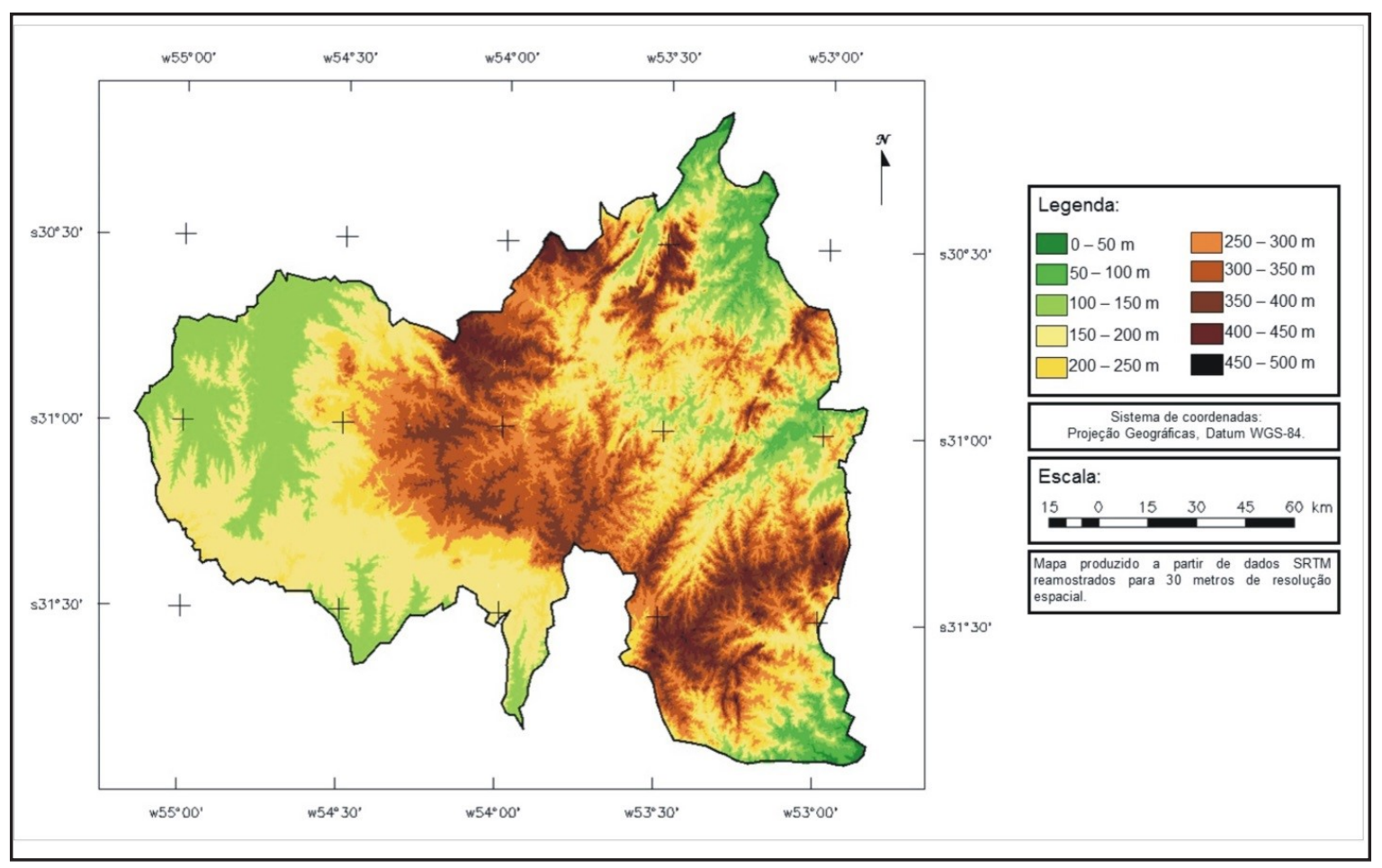

Figura 3 - Mapa hipsométrico dos municípios do território do Alto Camaquã - RS

Tabela 3 - Quantificação das classes altimétricas do território do Alto Camaquã - RS

\begin{tabular}{|c|c|c|}
\hline \hline Hipsometria $\mathbf{( m )}$ & $\mathbf{k m}^{\mathbf{2}}$ & $\mathbf{\%}$ \\
\hline $0-50$ & 65,89 & 0,29 \\
\hline $50-100$ & 744,34 & 3,24 \\
\hline $100-150$ & $4.168,40$ & 18,14 \\
\hline $150-200$ & $5.737,88$ & 24,97 \\
\hline $200-250$ & $3.404,39$ & 14,82 \\
\hline $250-300$ & $3.255,23$ & 14,17 \\
\hline $300-350$ & $3.262,80$ & 14,20 \\
\hline $350-400$ & $1.812,21$ & 7,89 \\
\hline $400-450$ & 517,55 & 2,25 \\
\hline $450-500$ & 8,76 & 0,04 \\
\hline Total & $\mathbf{2 2 . 9 7 7 , 4 5}$ & $\mathbf{1 0 0}$ \\
\hline \hline \multicolumn{2}{|c}{}
\end{tabular}

altitude (300 - 350 metros) ocupam a maior parte da extensão territorial (86,30\%), o que equivale $19.828,70$ $\mathrm{km}^{2}$, nestas altitudes são encontradas as classes "campo" e "solo exposto".

Referente as altitudes ( 0 - 50 metros), (50 - 100 metros), (350 - 400 metros), (400 - 450 metros) e a altitude de (450 - 500 metros) correspondem às áreas de menor extensão com $13,70 \%$, totalizando $3.148,75$ $\mathrm{km}^{2}$, nestas altitudes são encontradas as classe "água" e "floresta" (Tabela 3 e Figura 4). Informações sobre a declividade conforme Guerra e Guerra (2009) referemse à inclinação maior ou menor do relevo em relação ao horizonte, são fundamentais para o planejamento ambiental, uma vez que podem solucionar ou prevenir problemas ocasionados por atividades agropecuárias. O mapa das declividades é mostrado pela Figura 5.

Através da análise do mapa de declividade observouse o predomínio dos relevos do tipo plano ( $0 \%$ a $5 \%$ ), e suave ondulado ( $5 \%$ a $12 \%$ ) em quase todo o território doAlto Camaquã, totalizando 84,40\% da área. Estas áreas correspondem às atividades agrícolas e ações de práticas conservacionistas. O percentual de declividade de $(0 \%$ a $5 \%$ ) compreende as terras cultiváveis permitindo o uso de máquinas pesadas, sendo preservadas as nascentes, rede de drenagem e as Áreas de Preservação Permanente, enquanto para declividade de (5\% a $12 \%)$ estabelece o 


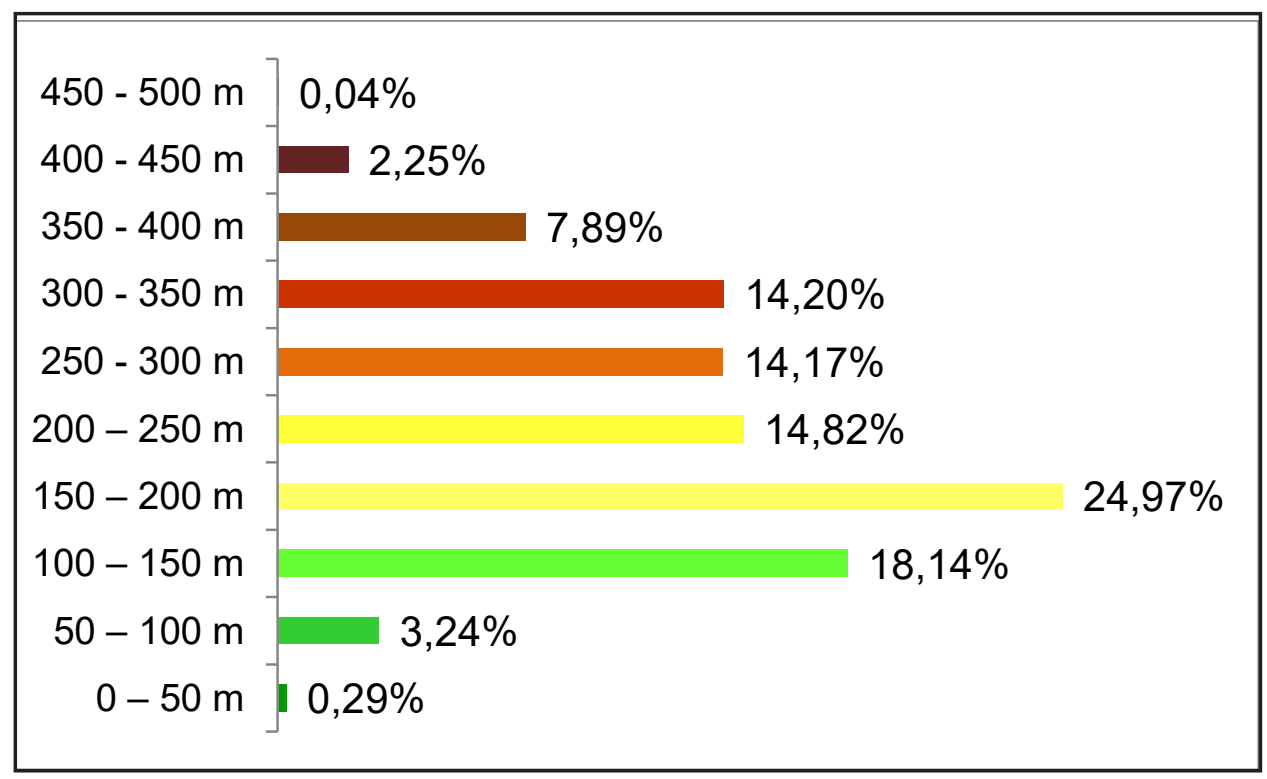

Figura 4 - Mensuração das classes altimétricas do território do Alto Camaquã - RS

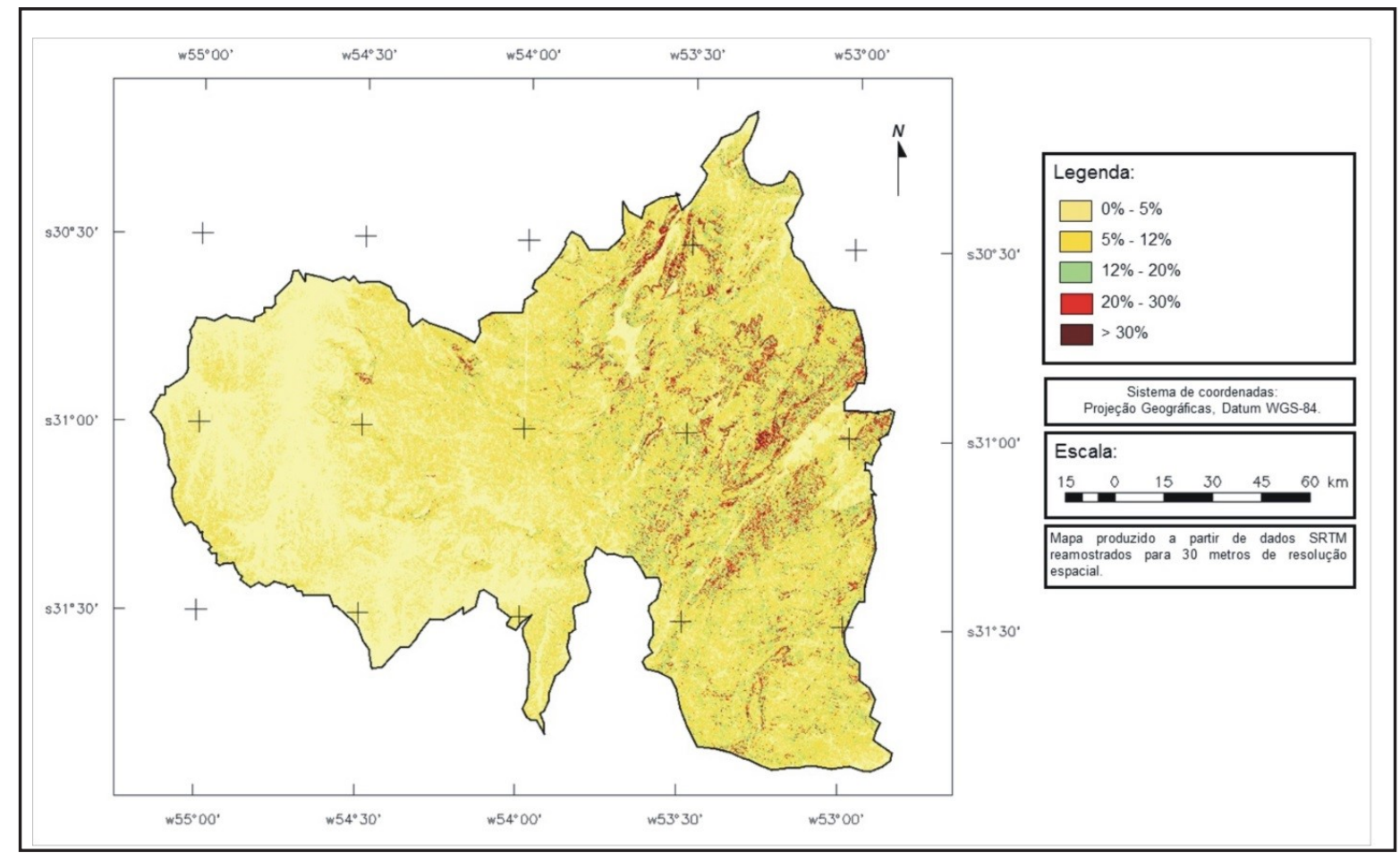

Figura 5 - Mapa da declividade dos municípios do território do Alto Camaquã - RS

limite máximo para o emprego de mecanização agrícola (De BIASI, 1992).

As demais classes de declividade (12\% a $20 \%)$ apresentam relevo moderado e a declividade com (20\% a 30\%) relevo ondulado totalizando $14,83 \%$ da área. Estas áreas de declividade correspondem às atividades agrícolas restritas, o pastoreio, o reflorestamento e a preservação da vegetação nativa. A declividade de (12\% a 20\%) e (20\% a 30\%) para De Biasi (1992) representa o limite máximo para urbanização sem restrições, enquanto para o meio rural as terras permitem cultivos com equipamentos de tração animal, reflorestamento podendo ser extraído para fins lucrativos com a exploração florestal.

A declividade acima de $30 \%$ corresponde ao relevo fortemente ondulado (com afloramentos rochosos e pedregosos), representa uma pequena porcentagem de 0,77\% localizada na região noroeste da área de estudo. Para De Biasi (1992), é o limite máximo para o corte raso de vegetação, a declividade a partir de $45^{\circ}$ só é permitida para a exploração se for sustentada por coberturas florestais, usadas para reflorestamento, cultivo de pomares e de vegetação permanente (Tabela 4 e Figura 6). 
Tabela 4 - Quantificação das classes de declividade do território do Alto Camaquã - RS

\begin{tabular}{|c|c|c|}
\hline Classes Declividade (\%) & Área Total $\mathbf{( k m}^{\mathbf{2}}$ & $\mathbf{( \% )}$ \\
\hline $0-5$ & $10.042,34$ & $43,70 \%$ \\
\hline $5-12$ & 9351,05 & $40,70 \%$ \\
\hline $12-20$ & $2.745,58$ & $11,95 \%$ \\
\hline $20-30$ & 660,78 & $2,88 \%$ \\
\hline Acima de 30 & 177,70 & $0,77 \%$ \\
\hline Total & $\mathbf{2 2 . 9 7 7 , 4 5}$ & $\mathbf{1 0 0}$ \\
\hline
\end{tabular}



Figura 6 - Mensuração das classes de declividade do território do Alto Camaquã - RS

\section{Conclusões}

Através da utilização dos Sistemas de Informação Geográfica aliados ao Sensoriamento Remoto, e suas técnicas de processamento digital das imagens, pode-se analisar os municípios que compõe o território do Alto Camaquã, contribuindo na elaboração dos mapas temáticos, hipsométrico e clinográfico. Com a classificação do uso e cobertura da terra foi possível fornecer bases para avaliar os diferentes usos, compreender a dinâmica e promover o melhor aproveitamento dessas áreas, possibilitando assim, uma utilização racional da área do estudo.

Na análise do mapa hipsométrico destaca-se as classes predominantes de 100 - 150 metros e $150-200$ metros de altitude, ambas as classes correspondem a $44,11 \%$ sendo característico das áreas de coxilhas e planícies. As áreas de menor altitude 0 - 50 metros e 400 - 450 metros totalizaram $2,45 \%$.

Quanto à análise do mapa clinográfico obteve-se como resultado o predomínio do relevo do tipo plano na classe $0 \%$ a $5 \%$ de declividade, abrangendo $10.042,34 \mathrm{~km}^{2}$ o que correspondente a $43,70 \%$ da área total do estudo.

A diversidade de fontes geradas pelo mapeamento pode ser armazenada, manipulada e analisada através de um banco de dados georreferenciado digitalmente, possibilitando o acesso de informações adequadas para a tomada de decisões, tanto no âmbito urbano quanto rural.

\section{Referências}

ANDERSON, J. R.; HARDY, E. E.; ROACH, J. T.; WITMER, R. E. 1979. Sistema de Classificação do Uso da Terra e do Revestimento do Solo para Utilização com Dados e Sensores Remotos: 1-78. Suprem-IBGE (série Paulo Assis Ribeiro), Rio de Janeiro.

ASRAR, G. Theory and applications of optical remote sensing. John Wiley \& Sons, New York. 1989. 734p.

BOLDRINI, I. I.; EGGERS, L. Vegetação campestre do Sul do Brasil: dinâmica de espécies à exclusão do gado. Acta Botânica Brasílica, Brasília, v. 10, n. 1, p. 63-66, 1997.

CASSOL, R. Zoneamento Ambiental elaborado com variáveis otimizadas estatisticamente, geradas por técnicas cartográficas. 1996. 292 f. Tese (Doutorado em Geografia Humana). Universidade de São Paulo, São Paulo, 1996. 
CURRAN, P. J. Principles of remote sensing. London: Ed. Longman, 1985, $282 \mathrm{p}$.

CHOMENKO, L. Pampa: um Bioma em risco de extinção. Revista do Instituto Humanista Unisinos (IHU - online). O Pampa e o monocultivo do eucalipto. Dezembro de 2007, no 247. São Leopoldo. Disponível em: <www. unisinos.br/ihu>. Acessado em: fev. 2015.

DE BIASI, M. Carta Clinográfica: Métodos de representação e sua confecção. São Paulo: Instituto de Geografia/USP, 1992. p. 43-45.

DEGRANDI, S. M. ecoturismo e interpretação da paisagem no ALTO CAMAQUÃ/RS: uma alternativa para o (desenvolvimento local). 2011. 197 f. Dissertação (Mestrado em Geografia). Universidade Federal de Santa Maria, Santa Maria, 2011.

FABRIS, L. C. Composição florística e fitossociológica de uma faixa de floresta arenosa litorânea do Parque Estadual de Setiba, Município de Guarapari, ES. Dissertação de Mestrado, Universidade Estadual Paulista, Rio Claro, 1995.

FEPAM. Fundação Estadual de Proteção Ambiental e Secretaria Estadual de Meio Ambiente - SEMA. Zoneamento Ambiental para atividade de Silvicultura. Vol. I e II. Porto Alegre, Janeiro de 2007.

FIGUEIRÓ, A. S.; SELL, J. C.; LOSEKANN, M. B.; DEGRANDI S. M. Compreensão da paisagem do Alto Camaquã: debate ambiental sobre o Bioma Pampa. In: Mercator, Fortaleza, v. 10, n. 23, p. 147-158, set./dez. 2011.

FITZ, R. F. Geoprocessamento sem complicação. 1a ed. São Paulo, SP, Oficina de textos, 2008. 160p.

GASSMANN, J. A transdisciplinary approach to rural development and conservation in the Alto Camaquã basin, Rio Grande do Sul, Brazil. Master thesis in Technische Universität München. Colaboration with Universidade Federal do Rio Grande do Sul: Porto Alegre, 2009.

GUERRA, A.; GUERRA, A. J. T. Novo dicionário geológico-geomorfológico. $7^{\mathfrak{a}}$ ed. Rio de Janeiro: Bertrand Brasil, 2009. 648p.

GUERRA, A. J. T; MENDONÇA, J. K. S. Erosão dos Solos e a Questão Ambiental. In: Reflexões Sobre a Geografia Física no Brasil. Rio de Janeiro. Bertrand Brasil, 2004.

LOCH, R. E. N. Cartografia: representação, comunicação e visualização de dados espaciais. Florianópolis: Ed. da UFSC, 2006.
LUCAS, A. S. Caracterização de nascentes no território do Alto Camaquã e a conservação Ambiental no contexto da pecuária familiar. 2013. 69 p. Relatório de conclusão de estágio supervisionado apresentado à Universidade Federal do Pampa, São Gabriel, RS.

MENESES, P. R.; ALMEIDA, T. (org.) Introdução ao processamento de imagens de Sensoriamento Remoto. Brasília: CNPq, 2012. 266 p.

MOREIRA, M. A. Fundamentos do Sensoriamento Remoto e Metodologias de Aplicação. 2 ed. Viçosa: Ed. da UFV, 2003.

NOVO, E. M. L. M. Sensoriamento Remoto: princípios e aplicações. São Paulo, SP: Editora Blucher, 2008. 333 p.

OVERBECK, G. E.; MULHER, S. C., FIDELIS, A.; PFADENHAUER, J.; PILLAR, V. P. Os campos sulinos: um Bioma negligenciado. In: PILLAR, V. D.; MÜLLER, S. C.; CASTILHOS, Z.; JAQUES, A.V.A (Org.). Campos Sulinos - conservação e uso sustentável da biodiversidade. Brasília: MMA, p. 26-41, 2009.

PACHECO, A. P., RIBAS, N. S., Sensoriamento Remoto aplicado ao Uso da Terra. GEODÉSIA online. Revista da Comissão Brasileira de Geodésia. Recife, v. 4, 1998.

PEREIRA NETO, O. C. Técnicas de Geoprocessamento aplicadas ao estudo da adequação do uso do solo em Bacia Hidrográficas. 1994, 124p. Dissertação (Mestrado em Sensoriamento Remoto). Instituto de Pesquisas Espaciais (INPE). São José dos Campos.

ROSA, R. Introdução ao Sensoriamento Remoto. 5 ed., Uberlândia: EDUFU, 2003, 228p.

RAMBO, B. A fisionomia do Rio Grande do Sul. Porto Alegre: Livraria Selbach. 1956.

SANTOS, A. F. Morfometria da microbacia hidrográfica do Ribeirão Faxinal Botucatu-SP e alterações em suas áreas de biomassa no período de 1972 a 2000. 70 f. Dissertação (Mestrado em Agronomia) - Faculdade de Ciências Agronômicas. Universidade Estadual Paulista Julio de Mesquita Filho, Botucatu, 2004.

STRECK, E. V.; KAMPF, N; DALMOLIN, R. S. D.; KLAMT, E.; NASCIMENTO, P. C; SCHNEIDER, P. Solos do Rio Grande do Sul. 2. ed. Porto Alegre: EMATER/ASCARRS, 2008. 222p.

STRECK, E. V.; KAMPF, N; DALMOLIN, R. S. D.; KLAMT, E.; NASCIMENTO, P. C; SCHNEIDER, P. Solos do Rio Grande do Sul. Porto Alegre: EMATER/RS; IFRGS, 2002. 
VALERIO FILHO, M. Gerenciamento de bacias hidrográficas com aplicação de técnicas de geoprocessamento. In: TAUK-TORNISIELD, S. M. et al. Análise ambiental: estratégias e ações. Rio Claro: CEA-UNESP, 1995. p.135-139.

VIEIRA, E. G.; ROVANI, F. F. M. O Uso da terra em Silveira Martins: uma nova perspectiva ou possibilidade por meio das geotecnologias. UFSM: Santa Maria, RS, 2009. 